\title{
Del discurso al cuerpo: opiniones sobre masculinidad de estudiantes universitarios en Guatemala.
}

\author{
From speech to body: Guatemalan university students' opinión \\ regarding masculinities.
}

José Herbert R. Bolaños Valenzuela*

\begin{abstract}
Resumen
Con el objetivo de identificar diversos niveles de reflexión y posicionamiento frente a la presión social que reconocen y enuncian para transformar las prácticas masculinas en las relaciones de género, se analizan los discursos recogidos en 11 grupos focales con estudiantes de la Universidad de San Carlos de Guatemala.Se encontraron varios tipos de discursos. Existe un discurso superficial que no reconoce el machismo que defiende; otro plantea la transformación como una necesidad personal, victimizándose de situaciones aparentemente injustas que enfrentan como hombres; un tercer discurso es el teóricoconceptual, en el cual los hombres aparecen posicionados ante la realidad, pero no parte de ella. Existe también un discurso basado en las experiencias personales, de reflexión auténtica y lleno de emociones, que ha pasado por el propio cuerpo. Cada discurso muestra un nivel diferente en el compromiso por transformarse, diversos avances, tensiones y cuestionamientos en torno al tema de la masculinidad; así mismo, ponen en evidencia retos que debe encarar la universidad al impulsar las necesarias transformaciones de la masculinidad.
\end{abstract}

Palabras clave: Discurso de los hombres, tensión con la masculinidad, prácticas cotidianas, argumentos actuales.

\begin{abstract}
This paper presents a speech analysis of 11 focus group data obtained during a masculinities research conducted with Guatemalan university students. The existence of social pressure to transform male practices in gender relations is named and recognized by students, pressure that leads to diverse reflection levels and stands. There are four speech models that can be identified in the analyzed data. The first, a shallow speech that

*Investigador de la Unidad de Investigación Profesional de la Escuela de Ciencias Psicológicas de la Universidad de San Carlos de Guatemala (USAC) y docente de investigación, sociología y psicología social de la comunicación, en la misma escuela. Psicólogo egresado de la USAC con maestría en Educación por la Universidad Internacional Iberoamericana (UNINI) Puerto Rico. Ha realizado investigación para diversas instituciones universitarias y ONG. Ha trabajado procesos de reflexión y acción en torno a las masculinidades en el Centro de Formación, Sanación e Investigación Transpersonal Q’anil. Correo electrónico: hbolanos@psicousac.edu.gt
\end{abstract}


doesn't recognize the male chauvinism it defends; another one that considers change as personal need and in which men are presented as victims of gender-related unfair situations; the next model is the theoretical-conceptual, a speech in which men state to have a deep understanding of reality and take a stand according to it, but don't see themselves as a part of that reality; and the last one, a speech based on personal experience, a result of authentic reflection that is filled with emotion and is mainly a result of bodily experience.

Each speech model shows a different commitment levels, a diversity of strives, tensions and questionings surrounding masculinities; likewise, they high lights the challenges that university must face on promoting the necessary transformations of masculinity.

Key words: Men's speech, tension with masculinity, day to day practices, current argumentations.

Fecha de recepción: Diciembre 2019

Fecha de aprobación: Junio 2020

\section{Introducción: El estudio de la masculinidad en estudiantes universitarios}

Los estudios sobre masculinidades han sido abordados en América Latina desde diferentes perspectivas, tan diversas que no es posible reconocer en ella un cuerpo de investigaciones único. Al explorar las investigaciones en cada región se pueden identificar diferencias en las temáticas y en los métodos y se pueden clasificar según lo que Batres, Ortiz y Chivalán (2011) llaman epicentros temáticos, es decir desde temas y metodologías más o menos comunes para cada país o región geográfica. Los autores reconocen dos epicentros principales en Latinoamérica: México y Sudamérica (haciendo énfasis en Chile, Argentina, Colombia, Ecuador y Perú) y exponen que en aquel momento la temática de las masculinidades se hacía más común y por diversos motivos: la influencia de organismos internacionales, las agendas académicas que reconocen la importancia del tema y los movimientos sociales. Muralles (2019) coincide en la referencia de los epicentros, expone que el estudio de la masculinidad en América Latina "inicia en los extremos y avanza hacia el centro" y agrega

"La relación entre la calidad de vida y producción académica es un factor que explica mucho de los momentos y ritmos en que la masculinidad ( $y$ cualquier otro tema) se abordó desde la ciencia en cada momento histórico y cultural' (p. 15)

Esa evolución de los estudios sobre masculinidades ha continuado con el mismo patrón (de los extremos al centro) y la región centroamericana sigue a la zaga de estos grandes epicentros, en buena medida replicando las prácticas que se observan en las otras regiones: 
a) la penetración académica, que se refiere escasamente al uso de conceptos provenientes del mundo anglosajón; b) la insistencia en la comprensión de la masculinidad a partir de roles específicos y sobre todo la paternidad; c) la asociación continua de la masculinidad con la violencia, al punto que con dificultad se les puede divorciar. (Batres, Ortiz y Chivalán, 2011: 22)

Para el caso específico de Guatemala, las investigaciones académicas aún son pocas y las sistematizaciones de procesos desarrollados por organizaciones sociales siguen siendo escasas, pese a que la frecuencia de estos procesos se ha mantenido en aumento durante la década. La falta de correspondencia entre el trabajo de los movimientos sociales y la investigación académica no es novedosa, ni exclusiva del tema en cuestión; tal brecha debe reducirse y es la academia la que debe acercarse al estudio de lo que ocurre en la sociedad, buscar para ello las categorías útiles en las teorías existentes, pero también construir las categorías que ayuden a comprender y transformar la realidad social.

En el empeño de cerrar la brecha, la única universidad pública del país (Universidad de San Carlos de Guatemala -USAC-) ha sido el escenario de dos estudios sobre masculinidades que se relacionan entre sí. El primero es el que ya se refirió, realizado por Batres, Ortiz y Chivalán (2011): "Tensiones y respuestas del modelo dominante de masculinidad en estudiantes de la Universidad de San Carlos de Guatemala". El segundo, cuyo informe no se ha publicado aún, lo coordiné durante los años 2018 y 2019, con el título: "Avances en las tensiones con el modelo de masculinidad dominante en estudiantes universitarios de Guatemala". El proyecto tuvo por objetivo la comparación de la tensión con las disposiciones de la masculinidad dominante entre los estudiantes del 2018 y los resultados publicados en el 2011. Para ello, desarrollamos una metodología multimétodo secuencial (Ruiz Bolívar, 2008), aplicando (en 2018) un cuestionario tipo Likert basado en el usado en el proyecto de 2011 y produciendo información a través de grupos focales (en 2019) para realizar un análisis del discurso de los estudiantes universitarios.

Al iniciar el análisis de los resultados de la primera fase del estudio, la cuantitativa, se fueron evidenciando avances en las tensiones con el modelo de masculinidad dominante ${ }^{1}$, es decir, un posicionamiento de duda y cuestionamiento ante los mandatos que se reproducen en la socialización masculina. Sin embargo, conforme se profundizó en el análisis se encontraron contradicciones y sobre todo mucha duda. Es decir, los estudiantes más que estar en tensión (en contra) no sabían qué responder, estaban en duda, respondían con poca seguridad a los enunciados del cuestionario Likert. Por ejemplo, la forma explícitamente machista de un ítem hacía que lo rechazaran, pero expresaban acuerdo con un ítem menos explícito que sostuviera la misma idea. Estas inconsistencias en las respuestas las consideramos un paso importante en el camino al cuestionamiento y la tensión con el modelo de masculinidad dominante: no es legítimo socialmente el pensamiento abiertamente machista. Sin embargo, reconocimos en ellas el riesgo de estar recibiendo respuestas políticamente correctas, que al ser confrontadas

\footnotetext{
${ }^{1}$ Una publicación con resultados parciales del estudio es: Muralles, Alejandra (2018).
} 
con las prácticas nos mostrarían que los avances concretos son menores que los avances discursivos y aunque esto es generalmente así, queríamos saber qué tanto se distancian el discurso y la práctica. En la segunda fase del estudio, la cualitativa, ahondamos en ello y parte del análisis de esa fase es discutido en este artículo, con la intención de identificar los retos que debe asumir la Universidad para transformar la vivencia de la masculinidad que tienen los estudiantes en particular y los hombres en general.

\section{¿Con quienes dialogamos y sobre qué?}

En el 2019 realizamos 6 grupos focales como parte del estudio principal y 5 grupos focales en el marco de la tesis de grado de Muralles (2019), la cual profundiza en una de las disposiciones exploradas por el estudio principal. En total, 42 estudiantes universitarios participaron en los grupos, pertenecen a diferentes unidades académicas (Facultades y Escuelas) de la USAC (12 psicología, 5 ciencias jurídicas y sociales derecho-, 4 medicina, 4 agronomía, 3 ciencias económicas, 3 historia, 2 ciencias químicas y farmacia, 1 humanidades, 1 arquitectura, 1 medicina veterinaria, 1 comunicación, 1 ingeniería, 3 no respondieron); tienen entre 18 y 29 años, todos son solteros y ninguno tiene hijos; se identificaron como heterosexuales 28 y 13 no heterosexuales (gay, bisexual, homosexual, no heterosexual) y 1 no respondió. De los 42 , 14 reportaron tener empleo. Respecto a religión sólo se tiene los datos de los grupos focales del estudio principal, se autoidentificaron: 8 católicos, 4 evangélicos (o cristianos), 10 sin religión (ateo, agnóstico, laico o sin religión), 1 no respondió. No muestro esta diversidad con la pretensión de que la información se considere generalizable, sino para evidenciar la heterogeneidad de los participantes, pues, como se verá, la clasificación que hicimos de los discursos es transversal a todas las características mencionadas: edad, religión, orientación sexual, situación laboral, etc. Por motivos éticos de confidencialidad se solicitó el consentimiento informado, acordando que sus nombres serían cambiados si fuera necesario, aunque cómo se trabaja con hablas grupales esto último no ha sido necesario.

Para cada grupo focal se tenía una guía de preguntas diferente, pues se buscaba explorar elementos de las disposiciones de la masculinidad dominante ${ }^{2}$ que dan cuenta de la relación entre éstas, de las contradicciones que contienen y de la vivencia de los actuales estudiantes de los mandatos asociados a la masculinidad dominante.

Las guías de los grupos focales tenían preguntas relacionadas con las disposiciones de la masculinidad dominante: paternidad, pareja, proveeduría, éxito, heteronormatividad; también con los cambios en la masculinidad y el contexto, la migración, la violencia y la sexualidad. También se presentaron resultados de la fase cuantitativa para conocer los argumentos e interpretaciones de los estudiantes al respecto.

\footnotetext{
2 Para comprender el uso de los conceptos "disposición" y "masculinidad dominante" en este proyecto se pueden revisar los textos ya referidos de: Batres, Ortiz y Chibalán (2011) y Muralles (2018 y 2019).
} 
Quisimos realizar grupos focales en los que participaran estudiantes con alguna característica en común, para explorar las diferencias en sus interpretaciones sobre algunos temas en particular; sin embargo, no pudimos realizarlos. Pensábamos en grupos de estudiantes: religiosos, que fueran padres, indígenas y mayores de 30 años (un grupo por cada característica). El tiempo del que disponíamos para realizar la producción de información se agotó antes de alcanzar a convocar y realizar tales encuentros. Esto se debió a cuatro aspectos que consideramos importantes de considerar al estudiar el tema de masculinidades: a) Algunos estudiantes se negaron a participar cuando se enteraron del tema, reconociendo que no quieren hablar de masculinidad; b) Otros presentaron excusas evidentes, como decir que tenían que asistir a clase en el horario del grupo, pero les vimos permanecer en actividades de ocio durante la realización del grupo; se niegan a hablar de tema, sin reconocerlo abiertamente; c) Varios estudiantes se comprometieron a asistir al grupo focal, pero luego no asistieron, en ocasiones presentaron excusas, pero la mayoría simplemente no asistió; y d) A los participantes del grupos focales les fue difícil referir a otros compañeros que quisieran participar en el estudio, interpretamos esto como temor de ser expuestos ante conocidos por haber participado en un estudio sobre masculinidades. Lograr la realización de grupos focales fue tomando más tiempo del que habíamos considerado necesario y tuvimos que interrumpir el proceso, aunque teníamos aún varias temáticas por abordar.

En contraparte a esta dificultad para asistir y participar, los participantes del estudio se mostraron -en general- muy dispuestos al diálogo, hablaron con confianza. Y, al terminar los grupos, se referían al espacio como una oportunidad que no sabían dónde buscar, una experiencia que les gustaría repetir y una necesidad que muchos hombres no reconocen, pero sí tienen. De esa cuenta, además de agradecer su participación, es importante decir que el análisis realizado no se elabora como un juicio sobre esas experiencias e interpretaciones, sino como una descripción de realidades subjetivas que se hacen evidentes en los diálogos y que muestran la realidad social en torno al tema de las relaciones de género y la construcción de la masculinidad en el contexto estudiado.

\section{Analizar el discurso y sus contradicciones}

El análisis del discurso pretende identificar aspectos ideológicos -entre ellos las relaciones de poder- que no son explícitos en la lectura (o el diálogo) cotidiano. Vicente Manzano (2005) propone al menos tres grandes pasos: analizar el contexto, analizar el contenido denso del mensaje y generar un modelo para mostrar los aspectos que el discurso esconde y se desean revelar.

Los grupos focales se diseñaron para ayudar a los estudiantes a identificar y reflexionar sobre sus contradicciones y conflictos entre los mandatos aprendidos y las demandas sociales de transformaciones, mostrando que la vivencia de la masculinidad es un proceso en conflicto tanto a nivel personal, como a nivel grupal y social; siendo los conflictos entre individuo y grupo, los más claros para los participantes.

Ya que el diálogo se desarrolló en torno a las contradicciones y los conflictos, los estudiantes tenían la oportunidad de posicionarse frente a determinadas situaciones se 
evidenciadas en los grupos. En ocasiones, esa posición se planteaba como una afirmación de la propia ideología machista, pero en otros casos les permitió darse cuenta de su contradicción, e incluso fue planteada como cuestionamiento por parte de los mismos participantes. La riqueza del diálogo mostró que en algunos temas (como la homofobia) los estudiantes tienen acceso a más información y conocen el discurso políticamente correcto; pero en otros temas (como la asociación de lo público con lo masculino y lo privado con lo femenino) aún son legítimas afirmaciones fuertemente machistas. Esto se traduce en que los hombres se consideren a sí mismo "menos machistas" por los avances discursivos en algún tema, pero no han identificado aspectos del pensamiento machista que reproducen (en el mismo u otro tema) y tampoco las prácticas machistas que sostienen en su cotidianidad.

Los grupos focales, por tanto, nos ofrecen evidencias tanto de la corrección política con que se abordan algunos temas, como de las prácticas que esa corrección política esconde. Por ejemplo, al referirse a la violencia intrafamiliar respondieron con un discurso muy correcto que condena la violencia física contra las mujeres, a la vez que evidencia la ausencia de información y conciencia respecto a otras formas de violencia contra la mujer; muestra, además, que la violencia contra otros y otras integrantes de la familia sigue invisibilizada como parte de la misma lógica de dominación masculina. Por ejemplo, al hablar sobre el rol de autoridad del hombre dentro de la familia, un participante dijo:

Yo siento que realmente lo que vino arruinar nuestra sociedad como tal fueron los Derechos Humanos porque sí, suena raro y extraño, pero en mi tiempo me pegaban y uno callado, si uno respondía [recibía]otro cuentazo. Ahora los niños... escucha uno cosas como <<si me pegas te voy a demandar porque ya me enseñaron que tengo derechos y te puedo meter a la cárcel>>. Pero yo pienso que nuestros padres tienen todo el derecho [de disciplinar con golpes]. (GF5³).

Además, cabe señalar que mientras el participante opinaba, otro asentía y ningún otro confrontó directamente lo que dijo. Esto ilustra la importancia de comprender que el discurso no es sólo la palabra, sino también los gestos, actos, silencios... toda la conducta del individuo y del grupo. Sin embargo, en este artículo he puesto el énfasis en el discurso hablado, pues es suficiente para el análisis propuesto.

Se trata de un análisis de los discursos con que se enuncia el machismo propio y el que se reconoce en el contexto de los estudiantes universitarios, a partir de lo propuesto por Manzano: "de qué va el tema, cómo se justifica, qué papel se le asigna al grupo ideológico, qué pronósticos se realizan, qué medidas se proponen, en qué aspectos se centran las críticas, qué se presenta como positivo y qué como negativo" (Manzano, 2005:12). Es decir, ¿cuál es la posición que los hombres asumen al identificar prácticas personales y grupales machistas? ¿qué argumentos exponen como

\footnotetext{
${ }^{3}$ Se identifica la fuente con las siglas GF (Grupo focal) seguido del número de grupo del cuál se tomó la cita. Los grupos 1 a 5 fueron realizados como parte del estudio principal, los grupos 6 a 11 corresponden a la tesis de grado de Muralles que se ha referido.
} 
justificaciones o explicaciones de tales conductas? ¿qué emociones y actitudes asocian en su experiencia personal a esas prácticas?

\section{¿Qué dicen los hombres? Los discursos que encontramos}

Conforme realizamos las lecturas de las transcripciones de los grupos focales para realizar el análisis central del estudio, logramos identificar diferencias importantes en los argumentos de los participantes, considerando las siguientes características: el nivel de reflexión evidenciada; la noción de realidad reflejada; el lenguaje usado; el posicionamiento ante el machismo. Distinguimos, entonces, cuatro modelos discursivos que no son categorías cerradas, sino referenciales, es decir, ayudan al análisis de los discursos sin ser una clasificación taxativa. Pretendemos con el modelo de análisis mostrar que en los diálogos fomentados aparecen diversas interpretaciones, niveles de reflexión y de compromiso. Además, es importante tomar en cuenta que diversas citas del mismo participante pueden corresponder a diferente modelo discursivo, por ejemplo, debido a que sobre un tema u otro tenga mayor o menor información, reflexión o experiencias. Es decir, hicimos la clasificación por cita (fragmento de un diálogo) y no como conjunto de citas de un mismo autor (todas las intervenciones de un estudiante), o asociando a varios estudiantes por alguna característica (como la orientación sexual o la carrera que estudia), o como discurso sobre un tema (aunque esas posibilidades de análisis también son interesantes).

Cada modelo discursivo se puede comprender como un conjunto de afirmaciones que, aunque no se relacionen directamente entre sí, dan cuenta de un mismo argumento en torno al machismo. Como dice Manzano:

Lo frecuente es que el discurso denuncie un hecho (o conjunto de hechos, o una situación), pero también que lo justifique, generalmente echando la culpa al enemigo, a las propias víctimas de la situación o a los contrincantes ideológicos (en cualquier caso, "los otros"). (Manzano, 2005:11)

En ese sentido, en el conjunto de citas que presento en cada modelo se refiere como "otros" a las mujeres, la sociedad o la naturaleza, otros hombres más machistas que ellos o de otras generaciones, de diferente carrera o práctica religiosa. También se distingue como "otros" a quienes no comparten la orientación sexual, señalándose mutuamente entre heterosexuales y no heterosexuales. Mientras, como parte del "nosotros" hay pocas referencias a un cuerpo colectivo, hablan con más frecuencia desde el yo (individual). Las ideas que dan sustento a estas nociones de "los otros", son analizadas con bastante amplitud por Galtung (2016), quien muestra cómo desde la religión, el idioma, el arte y la ciencia (entre otros elementos) hay una construcción del "otro" que no sólo le jerarquiza, sino que le despersonaliza. Parte de ese proceso se evidencia en un detalle de las referencias que encontramos: en general, los hombres hablan desde el "yo" individual (pocas veces desde el nosotros) y hablan sobre "los otros" y "las otras" como colectivo (en plural). 
Existen muchos elementos más que se pueden analizar en los discursos recogidos, sin embargo, para este artículo consideramos suficientes las categorías mencionadas antes. Con base en ellas presento una breve descripción de cada modelo discursivo, seguida de ejemplos de las citas que clasificamos en esa categoría.

\section{a) El discurso superficial:}

- Nivel de reflexión: se plantea como reflexión personal, desde un lugar individual. Los sujetos hablan de sus reflexiones como resultado de procesos puramente racionales e individuales, escasamente influenciados por procesos colectivos 0 producidos por experiencias significativas contrarias a la socialización.

- Concepción de la realidad: argumenta sobre la realidad como estática. Utiliza referencias como "siempre ha sido", "así debe ser", etc. lo que refleja poca expectativa transformaciones de la realidad y, por tanto, poco compromiso con los cambios.

- Lenguaje: utiliza el lenguaje coloquial y pocos términos técnicos, los cuales, igual que los escasos conceptos teóricos, aplica con frecuencia de forma inadecuada.

- Postura ante el machismo: justifica el machismo consciente o inconscientemente; atribuye la responsabilidad de su conducta a la sociedad (por ejemplo, a las mujeres como principales socializadoras) y se considera incapaz de transformarse (ya sea en alguno o en varios aspectos. Las prácticas que refleja y legitima sostienen el machismo abiertamente o de modo sutil.

Las primeras citas con que ilustro este modelo reflejan la concepción de la realidad estática, a partir de la reproducción de los roles de género y los valores machistas. Además, muestran una concepción de los roles masculinos como una condición universal.

Pero hay cosas que no van a cambiar nunca, siempre va a haber homofobia. (GF1).

El papá, mi papá era el que proveía y entonces aprendí que ese era mi papel, mi papá tenía como tres trabajos. Ese rol se entiende en el núcleo familiar. (GF5).

Proteger a la familia, es enseñarles a tus hijos que también tienen que asumir quién manda, quién es el hombre de la casa. (GF5).

Esa supuesta universalidad de la experiencia masculina es complementaria de una experiencia femenina, que también se supone universal. En la cita, además, se muestra que el nivel de reflexión es individual:

Una vez escuché un comentario de que los hombres siempre van a querer ser el primero en la vida de una mujer y las mujeres siempre van a querer ser la última en la vida de un hombre. Yo creo que es un comentario muy acertado, yo en lo personal creo 
Revista Punto Género N.ำ 13. Junio de 2020

ISSN 0719-0417 / 25 - 49

que es así. (GF2)

Tal como ocurre con alguna de las anteriores, la siguiente cita muestra la fuerte influencia del padre en la reproducción de los roles de género. Los estudiantes no advierten que ese rol está construido por la ideología machista y admiran el esfuerzo del padre por cumplirlo, se identifican con él y esperan alcanzarlo.

Pues tal vez para mí lo difícil de ser hombre es (...) llegar a ser la cabeza de mi familia en algún momento, si yo quiero llegar a tener familia. Yo lo miro en mi casa y mi papá pues él es mi héroe. Él hace cosas que yo digo que todavía me falta para llegar a hacer todo eso. (GF9).

En estas otras se hace evidente el acuerdo con las prácticas machistas. Desde la consideración de la mujer como propiedad y como objeto sexual, hasta el pacto masculino que se demuestra al considerar a la mujer como propiedad de otro y por tanto una deslealtad acercarse sexual o románticamente a ella, también se demuestra al encubrir la infidelidad de otros hombres.

Yo si respeto las cosas ajenas, lo del vecino es del vecino. No comparto esa idea... ninguna de las chicas con las que he andado tenía novio en ese momento. Al menos eso me dijeron. (GF3).

¿Ustedes han visto la lucha libre? Allí hay títulos verdad y el ejemplo que doy es que ese título tiene dueño, pero existen las posibilidades de que alguien más lo gane. Entonces cuando uno lo gana uno solo quiere mantener el título y cuando tocan el título eso lo molesta a uno; pasa con esto si yo ya estoy con ella, pero viene y me hacen lo mismo me voy a molestar, si yo hago eso el tiempo me lo va a hacer pagar. (GF3).

Ahora, si me decís que era novia de un cuate ${ }^{4}$, aunque ellos hayan terminado yo sí me la pensaría. Mucho más porque él es cuate, más que por alguien que no conoces. (GF3).

El poder es otro de los temas en que se evidencia la legitimización de la estructura patriarcal. Desde el discurso superficial, se legitima abiertamente la dominación por el simple hecho de que ésta es agradable o porque la socialización la ha normalizado. Aunque se advierte en este ejercicio de poder una injusticia, no se denuncia como tal y se presenta como si no fuera posible transformarla.

No me lo van a negar, pero tener el control y el dominio de algo, pues no se siente mal y seguirlo teniendo después de estar en el matrimonio, la mayoría pensaría: "jah! Eso está bien". (GF2).

Por ejemplo, nosotros no estamos acostumbrados a esas relaciones de poder, pero cuando encontramos el espacio las podemos practicar, a veces es inconscientemente, pero la mayoría de las veces es conscientemente que las hacemos y replicamos y no sólo en espacios donde nosotros sabemos que estamos en un plano mejor, sino que también en espacios tan comunes como con mis amigos, incluso con personas que tienen nuestra misma posición queremos tener el poder sobre ellos. (GF2).

${ }^{4}$ En Guatemala la palabra "cuate" es sinónimo de amigo o conocido. 
En estas citas, los estudiantes justifican sus acciones o se defienden ante las contradicciones que han reconocido, utilizando argumentos naturalistas o biologicistas. Además, en este ejemplo se muestra el uso inadecuado de referencias teóricas al aludir a la teoría de la evolución de Darwin, sobre un tema que, en todo caso, podría ser más cercano a la teoría Freudiana de las pulsiones, particularmente la libido.

Tengo una contradicción porque pienso que cuando me case quiero una mujer que sea virgen y casi nunca lo hablo, pero una vez, una chava me sacó el tema de conversación y me preguntó que por qué yo quería una mujer que fuera virgen "y tu siendo un puto" literal, "no sé" le dije, pero sí me gustaría, si me voy a dedicar a estudiar y quiero darle lo mejor, pues no sé, considero que es una cuestión biológica, le tengo que echar la culpa a Darwin. (GF3).

En los diálogos relacionados con la homofobia encontramos ejemplos de la postura abiertamente machista y claramente basadas en la individualidad, que no está en disposición de reflexionar colectivamente y (menos aún) de empatizar con la experiencia de otras personas.

Pues ahora ya se mira normal, ahora ya uno mira una pareja y [piensa] "ah, es una pareja homosexual". Y como dicen hay que respetarlos, sea la orientación que tengan, pues a mí me da igual. No es normal, no es normal pero ya se acepta. (GF10).

Yo soy evangélico, entonces no estoy en contra, pero tampoco estoy a favor, o sea, como dicen: si a mí no me molestan que hagan con su vida lo que quieren hacer; media vez no [me] molesten. (GF6).

También se muestra la dificultad para cambiar los patrones de socialización en torno al intercambio afectivo con otros hombres y sobre la iniciativa sexual (que se considera un rol exclusivamente masculino).

Yo hasta cierto punto me incomodo, me siento muy incómodo cuando alguien llega y me [hace gesto de abrazar] ajá, pasa... refiriéndonos a hombre [con] hombre, a veces sí es como "es mi espacio personal, respétame." (GF6).

Uno no sabe reaccionar cuando la mujer toma la iniciativa. (...) cuando ellas toman las riendas me siento hasta femenino. No es lo mío, sinceramente yo lo planeo y lo hago, [pero] si ella toma la iniciativa primero sí me confunde, me pone en una situación difícil. (GF10).

Yo no llegaría al punto de decirle a una mujer, así como "sos una puta o una perra" porque tengo una mamá, tengo hermana, abuela y primas. Y sí se mira mal, porque uno dice “iporque aflojan así tan rápido?”, en ese sentido es mejor estar en tiempo atrás cuando ellas se guardaban bien eso así de "no le voy a abrir las piernas a cualquiera", en cambio ahora uno se puede encontrar con cualquier mujer. (GF3).

Las representaciones de las mujeres presentes en este discurso corresponden a la ideología machista. En citas anteriores ya se les nombró como "vírgenes deseables para el matrimonio" o "putas deseables" como objeto sexual, también como propiedad en

${ }^{5}$ Utiliza el término "puto" para decir promiscuo. 
disputa (o ajena que debe respetarse). En estas otras, se les considera responsables del machismo o seres superiores a los hombres; es decir, desde la dicotomización de mujer buena o mujer mala. En la última cita se evidencia claramente la idea del eterno femenino, una esencialización de la mujer y la feminidad (Serna, 2014).

Yo soy de un departamento, en mi región el machismo lo marcan las mujeres. Suena paradójico, pero sí, así sucede. Porque son las madres de familia en las que le dicen: "las niñas a la cocina y los hombres con el machete al campo" y situaciones como estas. (GF6)

Porque la mujer también es importante. Es un ser más, quizás, más importante que el hombre, porque de ella surgimos todos, surgen todas las concepciones sociales que tiene el ser humano, no las patriarcales porque esa es otra diferencia. Pero sí todo lo que haya en... la cultura la hace, la cultura y la sociedad, lo que se nos va inculcando a nosotros porque con ellas crecemos primero. (GF1, Tormento).

\section{Los retos que evidencia el discurso superficial.}

Es fácil reconocer que este discurso representa el mayor reto para quienes buscan realizar intervenciones de cuestionamiento y transformación de las relaciones de género. Por un lado, porque este discurso es el más presente en la sociedad guatemalteca, pero, sobre todo, porque muestra poca disposición (a veces ninguna) a escuchar y reflexionar. Quienes se expresan sobre todo con este discurso, son individuos egosintónicos, consideran que las cosas están bien y se sienten bien con su actuar. Se suma a esto, la idea fuertemente arraigada en este discurso de que la realidad es estática, pues con esta mirada los esfuerzos por transformarla se valoran como poco efectivos, inútiles y hasta absurdos.

Ya que su perspectiva es bastante machista, desde este discurso pocas veces consideran válida la opinión y (aún menos) el cuestionamiento desde las mujeres, así como se descalifica las opiniones de los hombres disidentes del modelo hegemónico. Esa infravaloración (de hombres y mujeres) implica también que se les ataque y excluya. Además, suele encontrar respaldo a sus ideas en las autoridades a las cuales se somete, haciendo funcional el sistema patriarcal. Mientras, si encuentra una autoridad que le cuestione, suele buscar la forma de desacreditar, atacar o simplemente desobedecer a esa autoridad. Por tanto, se prevé dificultad para motivar a los hombres a participar en procesos que reflexionen sobre las relaciones de género, pues la mayoría de estos provienen de personas e instancias que desvaloriza. En ese sentido, el rol de la Universidad (y de las autoridades universitarias) es clave para señalar la necesidad desarrollar estos esfuerzos.

Como se puede intuir, con las citas que expuse, este es el discurso de quienes sienten orgullo de cumplir el rol tradicional atribuido a los hombres y de atacar a quienes no lo cumplen, así que motivarles a participar en procesos de cuestionamiento parece el primer gran reto a superar. Debiendo considerar, además, que se muestran fácilmente influenciados por la presión del grupo de hombres que piensan como ellos y que les 
excluirá y atacará si van mostrando cuestionamientos o disensos respecto al rol masculino tradicional.

Para lograr su participación en espacios de transformación, necesitarán procesos de sensibilización que deben partir de la experiencia y no de la teorización, que les vayan llevando poco a poco a tomar conciencia de la injusticia, de sus privilegios, sus contradicciones y de la responsabilidad compartida respecto a la desigualdad que se sostiene en las relaciones entre hombres y mujeres, entre los mismos hombres e incluso, en la relación consigo mismos.

Siguiendo las pautas de la masculinidad dominante, los hombres al sostener este discurso se mantienen en una posición defensiva y con facilidad tienen comportamientos agresivos. Esto dificulta mucho el trabajo en grupo, que es una condición facilitadora de los procesos de reflexión y cuestionamiento de la masculinidad. También se evidencia en este discurso la dificultad de reconocer la experiencia de otras personas como válida para reflexionar en conjunto. Desde este discurso, los hombres se mantienen en la posición de protagonistas de los procesos y suelen referir su experiencia como la más significativa, la que mejor muestra cómo "es la realidad" o como "debería ser". Por tanto, el reto es ayudarles a escuchar otras vivencias y considerar no sólo su validez y su importancia, sino, además, cuán útiles pueden ser para reflexionar individual y colectivamente, saliendo de la lógica de competencia y descalificación.

\section{b) El discurso de la necesidad personal}

- Nivel de reflexión: se plantea como reflexión personal, en ocasiones compartida con pares masculinos, provocada por algunas mujeres (como la pareja) o por figuras de autoridad. Con frecuencia las reflexiones se acompañan de una justificación o defensa.

- Concepción de la realidad: comprende la realidad como compleja, entendiendo que diversos contextos implican distintas percepciones de los hechos. Sin embargo, hace referencia casi exclusivamente a su percepción suponiéndola como la más válida, intenta explicar la experiencia de los otros imponiendo esa percepción. En su discurso no aparece la posibilidad de transformaciones sociales, sino la lógica del granito de arena.

- Lenguaje: cuida que su lenguaje refleje corrección política, utiliza algunos términos técnicos y conceptos teóricos, aunque en ocasiones de modo incorrecto.

- Postura ante el machismo: según su relato, el machismo es más fuerte que él, a pesar de sus esfuerzos. Responsabiliza a la sociedad, la naturaleza o a otras personas de las dificultades que afronta para su transformación, mientras se atribuye como éxito personal la transformación de algunos aspectos, que con frecuencia sobredimensiona. Aunque reconoce algunas prácticas machistas y se compromete con algunos cambios, se justifica (o defiende) respecto a otras 
que reconoce o le son señaladas; incluso niega algunas prácticas machistas, aunque sabe que las mantiene.

En este discurso identificamos como idea central la buena disposición de los hombres, que encuentra -casi siempre- obstáculos para realizar las transformaciones que (aparentemente) anhela. Por ejemplo, respecto a las diferencias por sexo en la educación de los niños y las niñas, o al impulso sexual que vivimos de forma diferente hombres y mujeres:

Por ejemplo, yo veo a un niño jugando con una muñeca y eso inconscientemente, aunque yo quiera pensar que está bien muy en el fondo voy a pensar que es homosexual. Tal vez es biológico, no sé. (GF1).

Sí suele haber diferencia, aunque no se desee yo creo que uno quisiera criarlos de la misma manera, pero por cuestiones sociales uno marca la diferencia. (GF1).

La corrección política, es otra de las claves para reconocer este discurso. Esta se nota como un esfuerzo de quienes utilizan el discurso y también como algo que reconocen en su contexto.

Tal vez no utilizamos el [término] "jefe de hogar" pero queda implícito el papel, tal vez los que somos agrónomos no lo decimos, pero si es algo que tenemos que ser. (GF5).

Yo creo que la mayoría de las personas son homofóbicas lo que pasa es que nadie lo dice (...) Por temor a que te tachen de homofóbico. (GF1).

Algunos de los cuestionamientos que se presentan tienen de fondo argumentos poco claros, por ejemplo, no se reconoce la condición de privilegio o el rol de opresor que los hombres tienen en determinadas circunstancias y se muestran en cambio como víctimas:

Estas mismas corrientes actuales LGBT está bien, pero oprimen a los que no están a favor, y pues yo creo que mientras yo no te ofenda también déjame pensar como yo quiera. (GF1).

Porque al final todo eso genera una presión en la que, si atendemos a la realidad, en la realidad en que vivimos es como "ok, yo [como hombre] tengo que tener trabajo, yo tengo que mantener un trabajo, tengo que mantener un puesto y un salario; y buscar ganar mejor". (GF6).

Otros cuestionamientos se resuelven con falacias que terminan legitimando los mismos u otros mandatos machistas. Por ejemplo, con relación a la dominación masculina a través de la tutela basada en la noción de que el intelecto de las mujeres es inferior al de los hombres. O al considerar que la vida laboral de las mujeres está sometida al permiso masculino y que ofrecerles la oportunidad de proveer es una deconstrucción de la masculinidad machista.

No todos están preparados para el poder, (...) si voy con una persona y le digo "mirá, te pago tu universidad y te pago todo" (...) Pero al año me dice 
que no le gusta la carrera, que se quiere cambiar de carrera, entonces uno entra en frustración, en cólera de decir "pero ¿por qué no lo pensaste mejor?, todo lo que gasté" esas contradicciones que vienen. Entonces uno dice (...) "la tengo que influenciar para que tome un camino correcto". (GF2)

Como hombre tiene que aportar a la casa, pero actualmente siento que ¿por qué no darle también a la mujer el beneficio de dar dinero hacia la casa?". (GF6)

Ocurre algo similar con esta cita reflejando la concepción de los roles de género como un modelo que ahora se ha invertido. En su intervención, el participante acusó (de forma sutil) a las mujeres y posiciona a algunos hombres como víctimas de esa inversión de los roles:

Mi mamá siempre trató de inculcarme mucho: "si encontrás una mujer que no sepa hacer nada, vos lo vas a tener que hacer". Entonces a mí me enseñaron, ella me enseñó, muchas de esas cosas. Creo que ahora ha cambiado mucho eso, los hombres somos más... son más hogareños incluso que las mujeres, e incluso papás luchones que son los que están solos con sus hijos. (GF5).

Contrario al anterior, apoyado en argumentos abiertamente machistas, en este modelo discursivo se identifican contradicciones y confusiones respecto a las prácticas que se consideran legítimas. En esta cita se evidencia de nuevo la corrección política, pero también se muestra como "los otros" son aquellos que toman posturas radicales (considera a los otros libertinos o muy conservadores):

Hay personas que pues no son tan ¿cómo decirlo? No pueden controlarse tanto, ese odio que le puedan tener a esas personas y de repente y esas marchas que ellos hacen desnudos y en frente de niños y eso tampoco está bien, pero tampoco justifica lo que las personas hacen de pegarles, de insultarlos. Entonces, yo sí estoy en contra, totalmente en contra de eso. Pero tal vez a veces sí hay que resguardarse un poco más y no hacer ese tipo de exhibicionismo. (GF9)

En las siguientes citas se muestra el temor a la vulnerabilidad, es decir, el límite de la transformación está marcado por un riesgo que no está dispuesto a correr: parecer poco masculino.

O sea, la vulnerabilidad que tenemos con las féminas, porque no es lo mismo hablar, por ejemplo, con un amigo, que decirle: "mirá vos, fíjate que hoy no sé, me siento mal y tengo ganas de llorar y demás" (...) que decirle a una mujer: "mirá, me siento mal y triste..." al menos en mi facultad, eso se percibe como falta de masculinidad y es totalmente rechazado. (GF2)

Por ejemplo, cada vez que vamos a halagar a un hombre y decir ese hombre es guapo y decimos "hashtag no homo" cada vez que usamos esa expresión es como para decir ok yo no soy homosexual, yo no soy gay, yo no soy bisexual...(GF6) 
Otro elemento de este discurso es que no se reconoce la refuncionalización de algunos mandatos, no se reconoce cómo el sistema coopta algunos procesos. Por ejemplo, se refiere que hay un cambio en la construcción de la masculinidad al permitir alguna sensibilidad y cuidado de la estética, sin notar que el modelo de belleza sigue siendo impuesto y los cuidados superficiales, mientras los hombres siguen sin atender su salud y otros aspectos relativos al cuerpo y la vida emocional.

Otra cosa son las cosas estéticas para hombres, vas a una barbería y te pueden hacer como faciales y tratamientos de barba y son otros hombres quienes dan el servicio, es como que ya no hay tanto machismo o ese pensamiento que el hombre tiene que ser tosco (GF1)

\section{Los retos que evidencia el discurso de la necesidad personal:}

Este discurso también es frecuente entre los estudiantes universitarios, aunque parece menos frecuente que el anterior, como decía, representa más que los demás la corrección política y, por tanto, les permite a los sujetos posicionarse desde un lugar versátil para adaptarse al grupo o la situación que enfrenten.

Se puede reconocer algo de egodistonía en este discurso, es decir, se reconocen algunas prácticas e ideas como no adecuadas o deseables, pero el discurso también muestra poca disposición al esfuerzo que requiere reflexionar sobre ellas y transformarlas. Por ejemplo, aunque refieran sentirse motivados, argumentan con facilidad falta de tiempo u otras dificultades logísticas para participar en procesos de reflexión y transformación de la masculinidad. Si el grupo que corresponde al discurso superficial dice abiertamente "no quiero", el discurso de la necesidad personal dice "no puedo", argumentando con excusas, así que encontrar la forma de motivarles puede ser igual de difícil que con el primer grupo.

Como evidencian las citas, al utilizar este discurso los sujetos se defienden o justifican. Ya que no viven como un ataque personal los cuestionamientos, no se muestran indiferentes ni agresivos ante quienes les cuestionan, pero en general dan pocas muestras de reflexiones profundas y cambios contundentes. En la misma línea, prestan atención a las mujeres en sus denuncias y cuestionamientos, así como a los hombres poco afines al modelo hegemónico de masculinidad, siempre que no comprometan gravemente su posición; sin embargo, sus planteamientos (su discurso) parece que más bien "siguen la corriente" al grupo en que se encuentren. Así, aunque consideren que algo sea injusto, en términos de género, no lo van a denunciar en un grupo de hombres machistas, aunque en un grupo disidente del mandato se pronunciarían profundamente indignados, tal como consideran que el grupo espera de ellos.

En este discurso se reconocen actitudes y contradicciones conscientes e inconscientes. Se puede decir que usando este discurso, los hombres se mienten a sí mismos sobre su propia experiencia y postura ante las injusticias, sus privilegios e 
incongruencias y que se explican a sí mismos como flexibilidad de pensamiento, lo que en realidad es una inconsistencia en la postura personal.

La confusión con términos y conceptos muestra que uno de los retos en los procesos reflexivos con hombres es aclarar esas confusiones, pero debe tenerse muy en cuenta que no se trata de enfatizar la formación teórica, sino de aprovechar las palabras técnicas para enunciar realidades y asociarlas con experiencias personales. En ese sentido, la Universidad, que se ha construido como espacio altamente racional y masculino, tiene que abrir espacios de diálogo (no de corte magistral sino horizontal) para abordar sentimientos, emociones y experiencias, y no tanto de exposición de teorías o argumentos (sin prescindir de estos, pero sí quitándoles el papel central que tienen en la academia).

El discurso de la necesidad personal pone en evidencia que los hombres necesitan salir de la posición individualista que el modelo hegemónico de masculinidad les ha construido y que mantienen, muchas veces, al avanzar en los procesos de deconstrucción. Superar ese discurso pasa por proponer caminos colectivos, separarse de los discursos tibios y las transformaciones "a medias" que en realidad terminan refuncionalizando las disposiciones de la masculinidad dominante. Esto implica un reto para quienes se posicionan desde el discurso en cuestión: deben asumir su responsabilidad, cuestionar su privilegio y superar su inacción. En otras palabras, deben asumir un compromiso político de transformarse y transformar sus espacios.

\section{c) Discurso Teórico - conceptual}

- Nivel de reflexión: Se plantea como reflexión teórica, colectiva, pero sobre aspectos que le son ajenos; en la que se abordan de forma crítica dinámicas de desigualdad y opresión, pero sin reconocerse actor en dichas dinámicas. Las reflexiones que se plantean están construidas "correctamente" en cuanto a forma, pero, en cuanto a fondo, no surgen de una experiencia propia de transformación.

- Concepción de la realidad: Argumenta la realidad como "objeto de análisis" a la que pertenecen los otros. Ese análisis se plantea a nivel de abstracciones teóricas que distan de una confrontación con la cotidianeidad, o en todo caso, se plantea a partir de la revisión de la cotidianeidad de los y las otras. Reconoce la complejidad de la realidad a diversos niveles y presenta explicaciones para los fenómenos que integran dicha complejidad. En este discurso, incluso se ofrecen a los otros "soluciones" para transformarse.

- Lenguaje: Hace uso de la "jerga de género", plantea argumentaciones elaboradas y en las que se vale de términos científicos, constructos teóricos y utiliza lenguaje vinculado al activismo social e incluso a los movimientos feministas. Usa un lenguaje del que se ha apropiado, pero que en realidad le es ajeno. Este discurso oscila entre la corrección política a fin de dar cuenta de una postura progresista y la incorrección política a propósito a fin de dar cuenta 
de una postura irreverente. En él se evidencia la construcción de un relato, no solo desde la superioridad académica, sino moral.

- Postura ante el machismo: Su conocimiento sobre la realidad machista, está acompañado de esfuerzos encaminados a la transformación, orientados por el reconocimiento de que hacer cambios es "lo correcto", más que por la plena convicción de replantear su vivencia de la masculinidad. Es consciente de algunos privilegios y hace esfuerzos individuales que percibe como trascendentales, pero no es consciente de sus contradicciones, por un lado. Por el otro, la postura de experto que asume no le permite acompañarse de otros en su proceso de transformación. Este discurso no permite identificar si hay un auténtico deseo por transformar y transformarse.

Algunos ejemplos del uso del lenguaje de este modelo de discurso son:

Para mí el matrimonio es un constructo social que valida la monogamia. (...)como bien decías tú, ya es ese constructo social conservador, al que aspiran porque es un modelo... (GF1).

Dentro de un colegio de hombres ser homosexual es un tema bien tabú, es un tema que está prohibido; de forma que, a estas personas, se les olvida básicamente adoptar la tradición heterosexual, siendo o no homosexuales. No sé si va el tema con la pregunta, pero nosotros se lo hicimos a varios compañeros homosexuales a punta de chingadera ${ }^{6}$, si lo quieren ver así, se les heteronormalizó. (GF5).

Como mencioné antes, en este modelo discursivo hay una distancia entre la realidad y el hombre que habla, en su discurso él no es parte de ese grupo de personas al que refiere:

Vemos cómo dicen que los grupos están de acuerdo con que las personas sean homosexuales, pero también las alejan, también los aíslan (...) que a ellos sólo los dejan que se junten con las mujeres principalmente y los hombres alejados de ellos. (GF2)

La mayoría de hombres dentro de la universidad, acá la mayoría son machistas, (...) [a la mayoría] sí les dan ganas de casarse por ese sentido... por mantener ese grado de "yo soy dueño de algo y quiero seguir teniendo el control de ese algo". (GF1)

Otra postura que asumen los hombres al hablar desde este discurso es la de explicar los fenómenos sociales con argumentos teóricos que tienen diversos grados de consistencia.

Entonces a la hora de ver en lo particular y estar en constante choque con lo general nos estamos dando cuenta de que la violencia existe y de que

\footnotetext{
6 Este término puede entenderse como "hostigamiento". Aunque puede tener una connotación menos grave (pasatiempo o broma), en el contexto se interpreta como referencia ambigua a conductas de acoso escolar.
} 
Revista Punto Género N ․ำ 13. Junio de 2020

ISSN 0719-0417 / 25 - 49

hay formas de evitarla o formas de poder denunciarla. Entonces yo sí considero que la violencia ha sido más visibilizada, no solamente por la institución de la familia, sino también por los órganos políticos se han dedicado a ver que los problemas de la sociedad y de los modelos económicos dependen en gran mayoría de esta violencia que el humano mismo no ha podido resolver. Entonces, yo sí creo que la violencia se ha logrado ponerle atención. (GF1).

Al final, [la homosexualidad] termina siendo natural ya sea para el control de la población porque ya estamos a ese punto (...) en el que (...) los otros controles, que son las enfermedades y las muertes por distintos factores que se dan en la naturaleza ya no están. Llegamos a un punto en el que es fase evolutiva poder llegar a controlarnos como población. (GF5).

En las siguientes citas se muestran reflexiones en las que se incorporan perspectivas académicas diversas, describen complejas relaciones sociales; lo hacen hablando en plural y desde una postura personal, pero sin llegar a ser reflexiones sobre experiencias propias.

En la sociedad se concibe mucho el tema de que el lugar que le corresponde a la mujer es atrás y es algo que o sea crea muchos problemas. ¡Qué choque fue para la universidad cuando ya las mujeres empiezan a incluirse en el poder! O sea ¿por qué no aspiramos a que hubiera una decana de una facultad? ¿O una rectora? Eso tendría que ser las acciones que tendríamos que tener. (GF1)

Son concepciones sociales muy arraigadas y muy conservadoras, que actualmente ya no cumplen su función o que más que todo ya no encaja con la perspectiva que tenemos nosotros como estudiantes universitarios y como jóvenes. (...) nosotros ya no aspiramos a casarnos por ese simple hecho de que esa construcción social no es que nosotros la decidamos, sino que ha sido impuesta de manera muy arbitraria. (GF1)

La siguiente cita da cuenta de aspectos de la realidad que desde este discurso se refieren como aspectos que deben transformarse, utilizando siempre el lenguaje académico, son reflexiones abstractas, enfocadas en el futuro deseable, más que en acciones concretas que se estén realizando.

Se trata de ver que las conductas de violencia ya no tienen que ser aceptadas, y que tenemos que empezar a generar un discurso en contra de las conductas de violencia y que si tenemos una conducta de violencia nosotros tenemos la responsabilidad de venir y denunciarla o de ver qué podemos hacer en contra de esa actitud que se está cometiendo. (GF1).

La última cita que presento sobre este discurso muestra un nivel de reflexión teórica abstracta, que de forma inconsciente argumenta desde los mismos mandatos que pretende denunciar. Empatiza poco con la situación de otras personas.

Pero es que es difícil, es que ceder el poder significa ceder privilegios, 
es algo que todos hemos escuchado que nacemos con privilegios, pero ¿qué pasa cuando nacés con privilegios y no sabés que los tenés? Yo como hombre sé que tengo privilegios, pero en mi cotidianeidad no sé cuáles son, 0 sea ¿qué privilegios puedo tener yo? ¿De ponerme un pantalón y que nadie me mire el culo? ¿El de no pintarme o andar oliendo a sudor y que nadie va a decirme nada porque los hombres no tienen que cuidarse? ¿Esos son privilegios? Yo así no lo veo como privilegio, lo veo más como una ventaja de poder comportarte de cierta forma y no que seas moldeado de una forma de ser. Entonces, inclusive esas mismas ventajas no son tan siquiera conscientes de ellas, y el mismo hecho de no ser conscientes nos da como esa fragmentación de la mente de decir "tengo miedo de perder ese poder o control, pero en realidad no sé cuál es ese poder o control”. O sea, no se han puesto a pensar ¿en el poder de qué? ¿controlar qué? Porque esa es la pregunta ¿qué ventaja? ¿sobre quién? ¿sobre qué? y ¿para qué? (GF2).

\section{Los retos que evidencia el discurso teórico - conceptual:}

El principal reto para que los hombres con este discurso profundicen en sus cuestionamientos y transformaciones es ayudarles a ver que el conocimiento es distinto de la reflexión. Que no por saber mucho se transforma realmente y en ocasiones la teoría sólo explica y justifica, sin cuestionar ni confrontar, porque muchas veces se queda en lo abstracto, sin considerar cómo los conceptos nombran experiencias personales o de hombres cercanos. Junto con esto, por tanto, se debe promover un espacio de escucha, pues cuando se habla con el discurso teórico-conceptual se tiende a explicar a los demás la comprensión de la realidad que se tiene y se olvida con facilidad la importancia de escuchar la perspectiva y las vivencias de otros.

Este discurso también muestra cómo los modelos de la masculinidad dominante se mantienen a pesar de esfuerzos y procesos realizados. Por ejemplo, el mandato de ser el héroe y salvador se vive también desde la perspectiva de quien pretende ayudar a los demás a entender o tomar conciencia, con los recursos teóricos que tiene. Así que se puede asociar este discurso con la actitud descrita como mansplaining, pues con este discurso los hombres también se acercan a los espacios de mujeres buscando ser los protagonistas. Como además se acercan asumiendo la postura del "hombre deconstruido", coloquialmente se ha llamado machoprogre a quien se comporta así. Si bien estas categorías coloquiales también se refieren a otras prácticas, entre los discursos que se están analizando, este es el que se acerca más a ellas.

Al participar en grupos de hombres para la reflexión de género, quienes mantienen este discurso suelen buscar roles de autoridad o liderazgo, buscan protagonismo y tienden a sentir que han avanzado más que otros en la reflexión y transformación. Es decir, mantienen el rasgo machista de la competencia en todos los ámbitos. Por otro lado, su sensación de llevar más camino recorrido le puede llevar a descalificar o querer dirigir la reflexión de otros, o bien, a sentir frustración por la lentitud o poca contundencia en los cambios que hacen otros hombres. Por ello, el reto es ayudar a 
los hombres a comprender que la experiencia de transformación es particular, diversa y que todas pueden servir como espejo para reflexiones valiosas, al construir espacios colectivos.

También hay otro reto, que se evidencia con este discurso y es que, asumiéndolo, muchos hombres centran su mirada en los procesos de los otros sin revisar su propia situación. Es necesario encaminar las experiencias de reflexión hacia la propia vivencia. Como decía, en procesos colectivos, que permitan verse a través de las experiencias de otros, pero no para evaluar a los otros, sino para crecer con ellos.

El nivel de cuestionamiento de quienes comparten el discurso teórico-conceptual es ciertamente mayor que el evidente en los discursos previos. Sin embargo, el reto para quienes han llegado a este nivel es la politización de sus acciones. Su discurso no muestra procesos organizativos entre los hombres; como decía, el discurso permite a los hombres acceder a espacios organizativos mixtos o de mayoría femenina, pero no les ha llevado (en la mayoría de los casos) a crear espacios masculinos de cuestionamiento y reflexión. Como decía un participante:

Las chicas están cambiando, no me atrevería a decir que somos los hombres los que estamos cambiando. (...) no obligados, pero como las chicas... ellas son las que hacen movimientos. Nosotros estamos muy cómodos en lo que somos y la sociedad nos acepta y si algo está aceptado ¿para qué lo vas a cambiar? (GF5).

La organización de espacios propios de los hombres para desarrollar sus procesos de transformación es uno de los principales retos en los ámbitos universitarios y de lograrlo se tendría no sólo la ventaja de abrir más espacios, sino sobre todo, de espacios orgánicos, integrados por y para los hombres. Hasta ahora, este discurso se presenta como un cuestionamiento a los otros (y en parte también a sí mismo), pero no es un llamado a la organización.

Ante este discurso rico en palabras para nombrar, denunciar y proponer, también es un reto logar que ese lenguaje de la academia (del mundo abstracto) se pueda acercar al lenguaje coloquial, pues esto puede ayudar a los hombres a trasladarlo a su vivencia concreta y a que, además de pensar sobre sí mismos, se permitan la experiencia emocional perdida en el proceso de socialización masculina: sentirse y vincularse emocionalmente con otros y otras; y, como se plantea a continuación, pasar del discurso al cuerpo.

\section{d) El discurso desde el cuerpo}

- Nivel de reflexión: Las reflexiones surgen a partir del planteamiento de su experiencia como parte de un contexto y una historia, similar a la de otros, pero personal. Este discurso gira en torno a vivencias que, en ocasiones, le han permitido $y$ en otras obligado, a pensar y pensarse desde diversas perspectivas. El discurso da cuenta de una visión menos individualista, en la que la colectividad se reconoce como origen de la construcción de las 
condiciones de la masculinidad y por tanto se reconoce que el camino para cambiar esas condiciones es compartido.

- Concepción de la realidad: Argumenta la realidad como compleja, sin pretender explicarla o entenderla en su totalidad. Debido a que este discurso está centrado en experiencias del día a día, la realidad se plantea desde esa cotidianeidad. Este discurso está caracterizado por ser un relato dinámico que contrapone experiencias y reflexiones, en el que la prioridad no está en la comprensión permanente y universal de los fenómenos sociales sino en el reconocimiento de una serie de procesos por los que tanto individuos como sociedad atraviesan.

- Lenguaje: Usa los conceptos para describir su experiencia y comprender la realidad en la que está inserta. En este discurso, no hay un sobre-cuidado del lenguaje en cuanto a los términos, lógicas y argumentaciones posibles, ya que la narración no es el centro de este, es más bien una herramienta para compartir las reflexiones hechas, así como para procurar nuevas. El lenguaje que se utiliza está caracterizado por una alta carga emocional, así como por alternar el uso de formas teóricas y coloquiales.

- Postura ante el machismo: Hace un esfuerzo por tomar consciencia, aunque mantenga contradicciones. Es consciente de que la deconstrucción inmediata no es posible y asume con mayor claridad la postura que toma ante el machismo. Esta postura es crítica y tiene un origen en experiencias personales, tanto difíciles como gratificantes; el discurso da cuenta de haber enfrentado situaciones en las que la violencia machista, en su diversidad de expresiones, ha implicado sufrimiento, así como de situaciones en que prácticas distantes de los mandatos patriarcales han implicado satisfacción, estas experiencias le permiten "darse cuenta" - "sentipensarse".

Este es el discurso que menos encontramos en los diálogos que provocamos. Sin embargo, hay algunos ejemplos que muestran reflexiones personales basadas en las vivencias de los participantes.

En mi caso hay muchas expectativas porque soy el único varón y hay cosas que no cumplí, y en diversificado llegué a dudar de mi orientación sexual, no porque me gustara otro hombre sino porque no llenaba esas expectativas, entonces siento que uno se carga. (GF1)

Yo estudié en un colegio solo de hombres y pues sí eran muy machistas, pero ahora conforme pasa el tiempo veo que han ido cambiando su forma de pensar. Entonces uno puede expresarse un poco más y eso es ya un poco más aceptado, y pues la carrera también tiene que ver aquí en psicología es un poco más abierto. (GF1)

En algunas referencias, se evidencia que tienen conciencia de su construcción desde el modelo de masculinidad dominante.

Yo pienso que sí, hablar entre nosotros es bien complicado porque denota debilidad y hasta cierto punto nadie quiere ser débil, todo el mundo quiere mostrar la cara de fuerte de resistente verdad. (...) En mi caso, yo no comento con nadie de mi círculo en el que me muevo, casi nadie sabe que estoy repitiendo. (GF5) 
También muestran algún nivel de conciencia de cómo participan de la reproducción del modelo machista de relaciones:

En las facultades se vive, o sea con los ingenieros, "este método es asi", "pero inge, yo el otro día..." "no, nada, usted se calla y sigue mi método (...) o no gana mi clase." Y uno replica esos métodos después, cuando le dicen "mirá vos yo hice este método...", "No, seguís mi método". Caés en ese rol del ingeniero porque decís "no, a mí me lo enseñaron como a mí me lo enseñaron, si querés, si no,volá". Entonces uno replica eso. (GF2).

El gay tiene la disponibilidad de ser promiscuo porque no se le va a tachar. Al contrario, entre más promiscuo más gay. Entonces como que te meten la semilla de que podés hacerlo, de que te podés liberar y de que entre más relaciones sexuales mejor y de que mejor si no te controlás, iliberate!Es más experiencia, más oportunidades de explorarte y explorar con alguien más. Pero no, es algo que sí se puede controlar. (GF7).

Otro aspecto que se puede evidenciar es que apuntan a transformaciones concretas que están ocurriendo, de las que son parte o que les son cercanas.

Yo antes tenía la mala costumbre de ser homofóbico, pero cuando me dieron la oportunidad de ser coordinador de un grupo de jóvenes [fue] que mi mentalidad cambió completamente, porque ya no excluyo, sino que, es más, me gusta integrar a todas las personas sin importar su orientación sexual, ahora puedo hablar de temas de eso porque he convivido con varias personas. (GF3)

Las mujeres tienen que tener su espacio, nosotros tenemos que generar esos espacios porque son espacios de los que nosotros no nos queremos alejar, entonces tenemos que dar esos espacios, otorgarlos... porque ellas ya los están conquistando, pero no tiene que ser así, nosotros tenemos que otorgar esos espacios y dejar que ellas vayan ocupando esos espacios y que también vayan desarrollándose en ciertas dinámicas, que nosotros nos hemos negado a aceptar que ellas también pueden. (GF6)

\section{Retos que evidencia el discurso desde el cuerpo}

Este discurso se identifica como el más avanzado y -tal como los otros -evidencia algunos retos que deben considerarse al trabajar procesos con hombres. Aunque al hablar desde este discurso se muestra que los hombres tienen mayor conciencia de sus privilegios, contradicciones y responsabilidades que al posicionarse desde los otros discursos, también pueden estar repitiendo mandatos de la masculinidad dominante. Por ejemplo, al considerar que por ser hombres tiene una misión trascendental que cumplir y actuar el mandato salvando a otros, al llevarles la conciencia y la verdad. Esto implica el reto de comprender que no se trata de salvar ni convencer a nadie, sino de promover procesos que pueden tener diversos finales; además, implica cuestionar constantemente las motivaciones (y las metodologías) de los procesos que se impulsen.

Desde la academia, se identifican tres retos concretos que deben asumirse: no cerrar los espacios que se han abierto quienes están en disposición y condiciones de hablar, de hacer y transformar los ámbitos universitarios; hacer eco a los procesos que ya 
están ocurriendo, apoyar a los colectivos y personas que trabajan por la equidad desde diferentes posiciones (ya sea como estudiantes, docentes, personal administrativo, aliados externos, etc.); y tercero, innovar en las propuestas que se realicen, salir de la acostumbrada lógica de repetir cursos (o experiencias) en serie, tomarse el tiempo para conocer a los grupos, para que los grupos se conozcan y se organicen. Esta creatividad y flexibilización de los procesos es uno de los mayores retos, considerando que las estructuras universitarias suelen ser rígidas.

Al trabajar en procesos colectivos, el discurso desde el cuerpo representa el reto de requerir atención por tiempo prolongado. Escuchar atentamente a quienes hablan de su propia vida puede ser cansado, incluso llega a ser cargado emocionalmente, por eso cuando este discurso está muy presente en un grupo, la experiencia es muy intensa y no siempre se está listo para vivirla y manejarla. En ese sentido, los hombres deben asumir el reto de sanar sus heridas, sus dolores, sus traumas. En la medida en que los hombres han sanado, usan el discurso desde el cuerpo en un tono reflexivo y conciliador, en cambio, cuando se expone desde el dolor, puede plantearse como reclamo o como agresión y en lugar de provocar diálogo y empatía, puede generar defensas y culpas.

Así, el reto de sanar conlleva comprender que los procesos son de largo aliento, de avances y retrocesos, más aún, de movimiento en todas direcciones y ritmos. Por tanto, se deben proponer procesos con momentos para hablar y para escuchar, para pensar y para sentir, para actuar y evaluar. No se trata, insisto, de explicaciones teóricas, sino de procesos que ayuden a los hombres a pasar por el cuerpo, por la vivencia. Y no se trata sólo de reconocer privilegios, contradicciones y responsabilidades, también hay que reconocer y mostrar los afectos, las esperanzas, las oportunidades y los pasos significativos que los hombres vamos dando en el proceso.

\section{Reflexiones finales}

Es claro que nadie sigue un solo modelo discursivo; los discursos aparecen mezclados a lo largo del diálogo. En diferentes temas, un mismo participante muestra diversos tipos de reflexión y de conciencia. También se muestra que el modelo de masculinidad dominante está siendo cuestionado en diversos aspectos y por varios sectores, en todos los grupos encontramos alguna tensión con el sistema patriarcal. Pero evidenciamos que, muchas veces, esa tensión viene de fuera, no es un cuestionamiento interior y es un cambio "obligado" por las condiciones, no el producto de la conciencia de una situación o condición injusta.

Por tanto, en su rol de institución social, la universidad debe provocar un cuestionamiento en el mismo sentido que las luchas sociales. Para ello es importante que se enfoque, no tanto en reproducir conceptos y teorías, sino en posibilitar condiciones de cuestionamiento que, llevando a reflexiones a partir de la realidad de los estudiantes, motiven a transformar las prácticas. Además, la universidad debe revisar sus propias prácticas para transformarlas, es decir, generar políticas que supongan una ruptura con el modelo patriarcal. 
No es un camino sencillo y a lo largo del artículo se ha presentado un conjunto de retos que van desde la dificultad de convocar a quienes sostienen un discurso superficial, hasta lograr que los procesos incluyan la sanación del dolor y sean un impulso para la transformación profunda y permanente no sólo de los individuos, sino también a nivel colectivo. Aunque se han presentado relacionados con cada discurso, es importante comprender que se trata de elementos que deben atenderse integralmente, en cualquier proceso que se proponga. Tal como los discursos no se encuentran aislados entre sí, tampoco los retos se presentan como elementos independientes.

Este trabajo ha explorado el discurso de los hombres como punto de partida para identificar esos retos, pero también hay que analizar los discursos de las mujeres, sus expectativas y valoraciones; aprender de sus experiencias en un diálogo responsable. Es oportuno profundizar en los matices que el discurso tiene según características, como ser disidente de la heteronormatividad, o afiliarse con determinada creencia religiosa. Además, en el contexto guatemalteco, no puede dejarse fuera del análisis el peso de la cosmovisión y la cultura, y de las relaciones entre pueblos indígenas, mestizos y ladinos. Seguramente, estudiar los discursos considerando estas características mostrarán mayores niveles de complejidad y otros retos que se suman a los expuestos.

\section{Bibliografía}

Batres, Jorge; Ortiz, Ana Izabel; Chivalán, Byron (2011): Tensiones y respuestas del modelo dominante de masculinidad en estudiantes de la universidad de San Carlos de Guatemala. Guatemala: Dirección General de Investigación (Digi) y Centro de Investigaciones en Psicología (Cieps) USAC.

Galtung, Johan (2016) "La violencia: cultural, estructural y directa", en: Cuadernos de estrategia, ISSN 1697-6924, No. 183, p.147-168. Disponible en: https://dialnet.unirioja.es/descarga/articulo/5832797.pdf

Manzano, Vicente (2005): Introducción al análisis del discurso. Sevilla: Disponible en https://personal.us.es/vmanzano/docencia/metodos/discurso.pdf

Muralles, Alejandra (2018): “¿Cómo son los hombres? Caracterización masculina en un cuestionario con estudiantes universitarios de Guatemala", en Revista de la Escuela de Psicología, Vol. II, No. 2, p.22-42.

Muralles, Alejandra (2019): "La heteronormatividad como disposición de la masculinidad dominante en estudiantes de la Universidad de San Carlos de Guatemala". Tesis (Licenciatura en Psicología). Guatemala: USAC, Escuela de Ciencias Psicológicas.

Ruiz Bolívar, Carlos (2008) "El enfoque Multimétodo en la Investigación Social y Educativa: Una mirada desde el Paradigma de la Complejidad”, en Teré: 
Revista Punto Género N.ำ 13. Junio de 2020

ISSN 0719-0417 / 25 - 49

revista de filosofía y sociopolítica de la educación. No. 8, p.13-28. ISSNe 1856-0970.

Disponible

en:

https://dialnet.unirioja.es/descarga/articulo/2785456.pdf

Serna, Mercedes (2014) "Rosario Castellanos y El Eterno Femenino", en: Anagnórisis. Revista de investigación teatral. No. 9, p.40-52, ISSN: 2013-6986. Disponible en: http://www.anagnorisis.es/pdfs/n9/MercedesSerna(40-52)n9.pdf 